\title{
Avaliação da composição físico-química de polpas de frutas comercializadas em cinco cidades do Alto Sertão paraibano
}

\section{Evaluation of physical and chemical composition of fruit pulp marketed in five cities in the Paraiba state-Brazil}

Thamirys L. S. Lima ${ }^{1}$, Cecylyana L. Cavalcante ${ }^{2}$, Diógenes G. de Sousa ${ }^{3}$, Pedro H. de A. e Silva ${ }^{4}$, Luiz G. Andrade Sobrinho. ${ }^{* 5}$

Resumo - O crescimento da indústria de frutas tem se baseado, em grande parte, à produção de polpas de frutas congeladas, a qual surge como uma alternativa de baixo custo para viabilizar a oferta de frutos nos períodos de safra e entressafra. O desenvolvimento desse mercado é resultado da produção de polpas congeladas por micro e pequenas empresas, muitas vezes implantadas com o intuito de melhorar a renda familiar de pequenos produtores rurais. A polpa de fruta comercializada deve apresentar características físicas, químicas e sensoriais similares da fruta in natura, bem como apresentar-se microbiologicamente segura e ainda deve atender aos padrões exigidos pela legislação brasileira vigente. Neste contexto, este trabalho tem como objetivo avaliar parâmetros físico-químicos (umidade, cinzas, acidez titulável, pH, sólidos solúveis em ${ }^{\circ}$ Brix, determinação da relação SS/AT, açúcares redutores e ácido ascórbico) em quinze polpas de frutas de diferentes sabores comercializadas em cinco cidades do sertão paraibano. Os resultados obtidos nesta pesquisa mostraram que $70 \%$ das polpas de frutas analisadas encontram-se de acordo com a legislação brasileira vigente.

Palavras-chave: polpa de fruta, composição físico química, legislação brasileira.

\begin{abstract}
The growth of the fruit industry has been based, in large part to the production of frozen fruit pulps, which appears as a low cost alternative to enable the fruit supply in periods during and between harvests. The development of this market is the result of frozen pulp production by micro and small companies, often introduced with the objective of improving family income of small farmers. The pulp of fruit marketed shall provide physical, chemical and sensory characteristics similar of fresh fruit, as well as present-microbiologically safe and still must meet the standards required by applicable Brazilian law. In this context, this work aims to evaluate physical and chemical parameters (moisture, ash, titration acidity, $\mathrm{pH}$, soluble solids in - Brix, determination of SS/TA ratio, reducing sugars and ascorbic acid) in fifteen fruit pulps of different flavors marketed in five cities located in Paraíba State - Brazil. The results of this survey show that $70 \%$ of the analyzed fruit pulps are according to Brazilian legislation.
\end{abstract}

Key words: fruit pulp, physic-chemical composition, Brazilian legislation.

\footnotetext{
*Autor para correspondência

Recebido para publicação em 10/03/2015; aprovado em 25/05/2015

${ }^{1}$ Graduanda em Engenharia de Alimentos da UFCG - Campus Pombal- Rua Jairo Vieira Feitosa, n 1770, Bairro Pereiros. CEP: $58840-000$.

E-mail: (thamirys12012@hotmail.com)

${ }^{2}$ Graduanda em Engenharia de Alimentos da UFCG -Campus Pombal-Rua Jairo Vieira Feitosa, n 1770, Bairro Pereiros.CEP:58840-000. Email:(cicileite@hotmail.com)

${ }^{3}$ Graduando em Engenharia de Alimentos da UFCG - Campus Pombal- Rua Jairo Vieira Feitosa, n 1770, Bairro Pereiros.CEP:58840-000. Email:(didi19_gomes@hotmail.com)

${ }^{4}$ Graduando em Engenharia de Alimentos da UFCG - Campus Pombal- Rua Jairo Vieira Feitosa, n 1770, Bairro Pereiros .CEP: 58840-000

E-mail: (henrique_pedroufcg@hotmail.com)

${ }^{5}$ Professor da Universidade Federal de Campina Grande (UFCG) - Campus Pombal- Rua Jairo Vieira Feitosa, n 1770, Bairro Pereiros. CEP:58840-000

Email: (luiz.gualberto@ccta.ufcg.edu.br)
} 


\section{INTRODUÇÃO}

A alta perecibilidade dos frutos é responsável por grandes perdas no período da safra, o que tem estimulado os produtores a aplicar e desenvolver processos tecnológicos visando aumentar o tempo de vida útil das frutas. Dentre os resultados desses esforços, têm-se a produção de polpas de frutas congeladas, de larga aceitação no mercado nacional, por geralmente manter as características organolépticas da fruta de origem (AMORIM, G. et al., 2002).

$\mathrm{O}$ mercado de polpas de frutas congeladas vem crescendo e apresenta um grande potencial mercadológico. Atualmente este setor da agroindústria encontra-se disseminado em todo o país, sendo um importante segmento da cadeia produtiva. Esse crescimento é resultado, em grande parte, da produção de polpas congeladas por micro e pequenas empresas, muitas vezes implantadas com o intuito de melhorar a renda familiar de pequenos produtores rurais (BUENO, S. M. et al., 2002).

Segundo a Instrução Normativa $N^{\circ} 01$, de 07 de janeiro de 2000, a polpa de fruta é definida como sendo "o produto não fermentado, não concentrado, não diluído, obtida de frutos polposos, através de processo tecnológico adequado, cujas características físicas, químicas e sensoriais deverão ser as provenientes do fruto de sua origem, e essas características não deverão ser alteradas pelos equipamentos, utensílios, recipientes e embalagens utilizadas durante o seu processamento e comercialização (BRASIL, 2000).

A polpa de fruta congelada é um produto que atende a diversos segmentos do setor de alimentos, sendo utilizadas no preparo de sucos, sorvetes, balas, produtos de confeitaria e lácteos como iogurtes. Sendo assim observa-se a necessidade de que as empresas produtoras de polpas busquem a adequação dos padrões de qualidade e de segurança de seus produtos aos níveis exigidos pelos consumidores cada vez mais conscientes e por legislações cada vez mais rigorosas (BUENO, S. M. et al., 2002).

A indústria de polpa de frutas tem como objetivos a obtenção de produtos com características sensoriais e nutricionais próximas da fruta in natura, segurança microbiológica e qualidade, visando não apenas a atender aos padrões exigidos pela legislação brasileira, como também às exigências do consumidor (AMARO, A. P. et al., 2002).

Além do fator nutricional, a conveniência é um fator importante para os consumidores. A conveniência, quando atribuída aos alimentos, relaciona-se com a facilidade de estocagem e de preparo para o consumo doméstico. O contínuo crescimento no consumo de frutas, associado às melhorias que estão sendo introduzidas na qualidade dos alimentos, indicam que as polpas congeladas de frutas tropicais devem continuar ganhando ainda mais mercado (COSTA, T. A. et al., 2003).

As características físicas, químicas e sensoriais, da polpa de fruta, deverão ser as mesmas do fruto de sua origem, para tanto a legislação brasileira estabelece valores mínimos e máximos dos seguintes compostos nas polpas de frutas: açúcares totais, acidez total, ácido ascórbico, $\mathrm{pH}$, sólidos solúveis e sólidos totais (BRASIL, 2000). Bem como é importante ressaltar que a composição química da polpa de fruta é influenciada pelo seu processamento e pelo tipo de fruta, bem como pelas características varietais da matéria prima, maturidade, clima, solo e práticas de cultura da fruta (PIO, R. et al., 2003).

Diante do exposto este trabalho tem como objetivo avaliar parâmetros físico-químicos ( $\mathrm{pH}$, umidade, cinzas, acidez titulável total, sólidos solúveis em ${ }^{\circ}$ Brix, Adeterminação da relação Sólidos Solúveis- acidez Titulável Total (ASS/AT), ácido ascórbico e açúcares redutores) de quinze polpas de frutas de diferentes sabores comercializadas nas cidades de Pombal-PB, Uiraúna-PB, Patos-PB, Sousa-PB e CajazeirasPB.

\section{MATERIAL E MÉTODO}

\section{Amostras}

Quinze (15) amostras de polpas de frutas congeladas foram adquiridas, em saquinhos de polietileno de $100 \mathrm{~g}$, em diferentes estabelecimentos comercias de cinco cidades do alto sertão paraibano: Pombal (03 amostras; sabores-cajá, abacaxi e acerola), Uiraúna (03 amostras sabores: tangerina, abacaxi com hortelã e goiaba), Patos (03 amostras sabores: graviola, manga e uva), Cajazeiras (03 amostras sabores: tamarindo, maracujá e caju) e Sousa (03 amostras sabores: ameixa, graviola e goiaba). A maioria das polpas analisadas é das marcas comerciais: Doce Mel, Brasil Polpas e Nossa Fruta, demonstrando assim que essas marcas são detentoras das vendas de polpas de frutas nas cidades onde as amostras foram adquiridas. Entretanto três amostras foram compradas diretamente de pequenos produtores e que não continham rótulos.

\section{Caracterização físico-química da amostra}

Os parâmetros físico-químicos medidos nas amostras de polpas foram $\mathrm{pH}$, sólidos solúveis totais, umidade, cinzas, acidez total titulável, determinação da relação SS/AT, açúcares redutores e ácido ascórbico. Cada parâmetro físicoquímico foi determinado em triplicata.

Todas as análises foram realizadas no Laboratório de Química, Laboratório de Tecnologia de Alimentos de Origem Vegetal e no Laboratório de Análise Sensorial do Centro de Ciências e Tecnologia Agroalimentar da Universidade Federal de Campina Grande - Campus de Pombal-PB.

\section{Procedimento experimental para a Umidade}

Pesou-se um cadinho de porcelana e verificou-se a massa do mesmo, em seguida, 5,0 $\mathrm{g}$ da amostra foram pesada no mesmo cadinho e aquecida a $105^{\circ} \mathrm{C}$ na estufa (STERILIFER) por exatamente 3 horas, após esse período, colocou-se a amostra no dessecador, ao esfriar, a segunda pesagem foi realizada, conforme a metodologia (INSTITUTO ADOLFO LUTZ, 2004).

\section{Procedimento experimental para a determinação de $\mathrm{pH}$}

A determinação do $\mathrm{pH}$ foi realizada pela imersão do eletrodo do pHmetro (LUCADEMA) em cada amostra até o pH ficar constante (INSTITUTO ADOLFO LUTZ, 2004).

Procedimento experimental para a determinação da acidez total titulável

Pesou-se 1,0 g de cada amostra em um béquer de 250,0 $\mathrm{mL}$ e dissolveu-se em $50,0 \mathrm{~mL}$ de água destilada e em 
seguida agitou-se com agitador magnético (MARTE AY-220) até a dissolução total da amostra. Em seguida foi realizada a titulação com solução de hidróxido de sódio $0,1 \mathrm{M}$ até uma faixa de $\mathrm{pH}$ entre 8,2 a 8,4 que foi medido através de pHmetro (INSTITUTO ADOLFO LUTZ, 2008).

Os teores de acidez total titulável foram quantificados de acordo com o ácido presente na fruta de origem da polpa, neste caso a acidez titulável em função do ácido cítrico foi determinado para as polpas de tangerina, abacaxi com hortelã, goiaba, cajá, graviola, maracujá e manga; o ácido málico foi quantificado para as polpas de acerola, caju e ameixa; e o ácido tartárico foi determinado para as polpas de uva e tamarindo.

\section{Procedimento experimental para a determinação de cinzas}

Pesou-se 5,0 g da amostra em um cadinho de porcelana. Em seguida, o conjunto foi incinerado na mufla a $550^{\circ} \mathrm{C}$, $\log \mathrm{o}$ após o conjunto foi retirado da mufla e colocado no dessecador para esfriar e ser pesado quando atingir a temperatura ambiente. As operações de aquecimento e resfriamento foram realizadas até peso constante (INSTITUTO ADOLFO LUTZ, 2008).

Procedimento experimental para a determinação do teor de ácido ascórbico

Pesou-se 2,0 g da amostra em erlenmeyer e adicionou $50,0 \mathrm{~mL}$ de ácido oxálico 0,5\% (gelado) e logo após titulou-se com a solução de Tillmans até o ponto de viragem (INSTITUTO ADOLFO LUTZ, 2008).

Procedimento experimental para a determinação da relação SS/AT

A relação SS/AT foi obtida por meio do quociente entre essas duas variáveis (sólidos solúveis e acidez total titulável) (INSTITUTO ADOLFO LUTZ, 2008).

Procedimento experimental para a determinação de açúcares redutores

Pesou-se $5 \mathrm{~g}$ da amostra em béquer de 100,0 $\mathrm{mL}$, adicionou-se 50,0 $\mathrm{mL}$ de água destilada, e em seguida levada ao banho-maria por 5 minutos á $40^{\circ} \mathrm{C}$. Após a amostra fria, adicionou-se $2,0 \mathrm{~mL}$ de acetato de chumbo e uma alíquota de sulfato de sódio, transferiu-se para uma balão de 100,0 mL e completou-se o volume, filtrou-se em erlenmeyer e em seguida realizou-se a titulação com a solução de Fehling até que a solução passe de azul a incolor com precipitado vermelho-tijolo (INSTITUTO ADOLFO LUTZ, 2008).

Procedimento experimental para a determinação de sólidos solúveis totais

Cada amostra foi homogeneizada e depois transferiu-se duas gotas da mistura para o refratrômetro tipo Abbé (INSTITUTO ADOLFO LUTZ, 2008).

\section{RESULTADOS E DISCUSSÃO}

\section{Umidade, pH e Cinzas}

A umidade de um alimento está relacionada com sua estabilidade, qualidade e composição (CECCHI, H, M., 2003) e os valores médios dos teores de umidade determinados nas amostras de polpas analisadas é apresentado na Tabela 1. Observa-se que os valores variaram de 2,66 a 16,25\%. Os valores obtidos na determinação de umidade das polpas em análise apresentaram limites inferiores aos citados por BUENO (2002) e CANUTO (2010).

A medida do $\mathrm{pH}$ é importante na análise de alimentos industrializados, a base de frutas, uma vez que está relacionada a retenção do sabor-odor de produtos de frutas, a estabilidade de corantes artificiais em produtos de frutas e bem como a verificação do estado de maturação de frutas (CECCHI, H, M., 2003). Na Tabela 1 é apresentado os valores de $\mathrm{pH}$ nas amostras analisadas e cujos valores variaram de 1,22 a 4,55. De acordo com a legislação brasileira vigente o $\mathrm{pH}$ em polpa de fruta pode variar de 2,2 a 4,6 (BRASIL, 2000) e nesse caso apenas a Amostra 04 Sabor cajá de Pombal apresentou $\mathrm{pH}$ menor que o permitido. $\mathrm{O}$ pH das polpas de graviola encontram-se próximos aos resultados descrito por CANUTO (2010). A polpa de manga apresentou resultados semelhantes aos obtidos por MACHADO (2007). Já as polpas de uva e tamarindo obtiveram valores próximos conforme os encontrados por CANUTO (2010). Houve divergência dos valores de pH das polpas de goiaba, cajá e abacaxi com os descritos por AMORIM (2002) e MACHADO (2007).

A cinza obtida na análise não tem necessariamente a mesma composição que a matéria mineral presente originalmente no alimento, pois pode haver perda por volatilização ou alguma interação entre os constituintes da amostra. Os elementos minerais se apresentam na cinza sob a forma de óxidos, sulfatos, fosfatos, silicatos e cloretos, dependendo das condições de incineração e da composição do alimento (CECCHI, H, M., 2003). O conteúdo de cinzas das amostras variou de 0,19 a $0,60 \%$, conforme mostrado na Tabela 1. Não há valor máximo ou mínimo exigido para cinzas em polpas de fruta na legislação brasileira (BRASIL 2000) e não foi encontrado na literatura valores referente ao teor de cinzas em polpa de fruta. 
Thamirys L. S. Lima, et al.

Tabela 1. Valores médios de Umidade, pH e Cinzas nas amostras de polpas analisadas.

\begin{tabular}{lcccc}
\multicolumn{1}{c}{ Amostra } & Cidade & Umidade $(\boldsymbol{\%})$ & pH & Cinzas $(\%)$ \\
\hline $01-$ Sabor tangerina & Uiraúna & $9,56 \pm 0,17$ & 1,91 & $0,23 \pm 0,00$ \\
$02-$ Sabor abacaxi com hortelã & Uiraúna & $13,22 \pm 0,68$ & 2,70 & $0,40 \pm 0,06$ \\
$03-$ Sabor goiaba & Uiraúna & $9,79 \pm 0,05$ & 2,44 & $0,46 \pm 0,05$ \\
$04-$ Sabor cajá & Pombal & $9,86 \pm 0,79$ & 1,22 & $0,35 \pm 0,00$ \\
$05-$ Sabor abacaxi & Pombal & $2,66 \pm 0,04$ & 2,70 & $0,21 \pm 0,02$ \\
$06-$ Sabor acerola & Pombal & $6,50 \pm 0,11$ & 2,80 & $0,19 \pm 0,01$ \\
$07-$ Sabor graviola & Patos & $13,49 \pm 0,06$ & 3,23 & $0,60 \pm 0,01$ \\
$08-$ Sabor manga & Patos & $16,25 \pm 0,10$ & 3,66 & $0,39 \pm 0,02$ \\
$09-$ Sabor uva & Patos & $10,70 \pm 0,03$ & 2,26 & $0,22 \pm 0,00$ \\
$10-$ Sabor tamarindo & Cajazeiras & $9,13 \pm 0,04$ & 2,77 & $0,36 \pm 0,02$ \\
$11-$ Sabor maracujá & Cajazeiras & $6,21 \pm 0,05$ & 3,29 & $0,25 \pm 0,01$ \\
$12-$ Sabor caju & Cajazeiras & $12,23 \pm 0,06$ & 4,55 & $0,28 \pm 0,01$ \\
$13-$ Sabor ameixa & Sousa & $8,62 \pm 0,10$ & 3,96 & $0,29 \pm 0,02$ \\
$14-$ Sabor graviola & Sousa & $4,74 \pm 0,00$ & 3,80 & $0,12 \pm 0,01$ \\
$15-$ Sabor goiaba & Sousa & $6,59 \pm 0,03$ & 3,96 & $0,33 \pm 0,01$ \\
\hline
\end{tabular}

Acidez Total Titulável, ${ }^{\circ}$ Brix e relação Sólidos Solúveis Totais/ Acidez Total Titulável (SST/ATT)

O teor de ácidos orgânicos em frutas varia de acordo com a espécie e o seu conteúdo diminui com o amadurecimento na maioria dos frutos tropicais devido à sua utilização no ciclo de Krebs ou a sua transformação em açúcares durante o processo respiratório (CHITARRA; CHITARRA, 2005). Na legislação brasileira é apenas controlado o teor mínimo da acidez total titulável para os sabores de polpas analisadas que varia de 0,30 a $0,90 \%$ (BRASIL, 2000) e de acordo com os dados mostrados na Tabela 2 todas as amostras analisadas estão dentro das normas da legislação vigente, sendo que os valores de concentrações de acidez total titulável nas polpas analisadas variaram de 0,25 a $2,18 \%$. Comparando os teores da acidez total titulável das amostras com outros trabalhos da literatura observa-se que os resultados obtidos para as polpas de goiaba apresentaram valores inferiores ao encontrado por PINHEIRO (2006), o mesmo acontece para a polpa de abacaxi e de manga que obtiveram valores bem abaixo dos descritos por BUENO (2002) e PINHEIRO (2006). Já para a polpa de cajá obteve-se resultados semelhantes aos descritos por PINHEIRO (2006) e inferiores aos de BUENO (2002). A polpa de uva apresentou resultados idênticos aos de BUENO (2002) e a para a polpa de maracujá foi obtido valor de acidez total titulável semelhante ao de RAIMUNDO (2009).

O teor de Sólidos Solúveis Totais ( ${ }^{\circ}$ Brix) é utilizado como uma medida indireta do conteúdo de açúcares, pois seu valor aumenta à medida que estes vão se acumulando no fruto. No entanto, a sua determinação não representa o teor exato de açúcares, pois outras substâncias também se encontram dissolvidas no conteúdo celular (vitaminas, fenólicos, pectinas, ácidos orgânicos), apesar de os açúcares serem os mais representativos e poderem constituir até 85 - $90 \%$ destes (CHITARRA; CHITARRA, 2005). A Instrução Normativa $N^{\circ}$ 01/2000 (BRASIL, 2000) controla o teor mínimo de sólidos solúveis ( ${ }^{\circ}$ Brix), que para os sabores de polpas analisadas varia de 5,5 a $11,0{ }^{\circ}$ Brix, e esse valor depende da fruta que deu origem a polpa de fruta. Nas amostras analisadas, o teor mínimo de sólidos solúveis, variou de 2,7 a 14,3 ${ }^{\circ}$ Brix, conforme mostrado na Tabela 2 e observou-se três (03) amostras analisadas apresentaram teores menores que o permitido pela legislação para esse parâmetro. Ainda pelos dados da Tabela 2, o valor médio de sólidos solúveis para polpa de goiaba foi de $7,1^{\circ}$ Brix e esse valor é compatível com os resultados obtidos por PEREIRA (2006); para a polpa de cajá o resultado foi semelhante com o descrito por MACHADO (2007) e o resultado para polpa de acerola foi semelhante com os de PINHEIRO (2006). A polpa de graviola da cidade de Patos obteve resultado bem próximo ao de PEREIRA (2006), para a polpa de manga o resultado obtido foi semelhante ao de BUENO (2002). As polpas de abacaxi, uva, tamarindo e maracujá apresentaram teores inferiores aos limites encontrados na literatura, indicando que pode ter sido adicionado um teor a mais de água nas polpas ou as frutas foram colhidas em período de chuva, o que promoveria a diluição dos sólidos solúveis conforme proposto por BUENO (2002).

A relação Sólidos Solúveis Totais/ Acidez Total Titulável (SST/ATT) indica o grau de doçura de um fruto ou de seu produto, evidenciando qual o sabor predominante, o doce ou o ácido, ou ainda se há equilíbrio entre eles. De acordo com CHITARRA E CHITARRA (2005), essa relação é uma das formas mais utilizadas para a avaliação do sabor, sendo mais representativo que a medição isolada de açúcares ou da acidez. Essa relação dá uma idéia do equilíbrio entre esses dois componentes. Quanto maior for esta razão, mais doces serão as frutas, sendo um importante atributo de qualidade das frutas, além de constituir uma forma usual para avaliar o sabor e selecionar a matéria-prima para o processamento (MUSSER et al., 2004). Entre as polpas de frutas avaliadas, conforme mostrado na Tabela 2, verifica-se que a amostra que apresentou a maior relação SST/ATT foram as polpas de manga e de caju, com média de 57,0 e 28,0, respectivamente. 
Os valores obtidos para as polpas de cajá são semelhantes aos o mesmo autor. LIMA (2012) ao avaliar a relação SST/ATT encontrados por MACHADO (2007), já para as polpas de de polpa de acerola encontrou resultados bem próximos ao goiaba e manga, os valores diferiram quando comparados com obtido em análise para a polpa de mesmo sabor.

Tabela 2. Valores médios da Acidez Total Titulável (\%), Brix e relação Sólidos Solúveis Totais/ Acidez Total Titulável (SST/ATT) nas amostras de polpas analisadas.

\begin{tabular}{lccc}
\hline \multicolumn{1}{c}{ Amostra } & Acidez Total Titulável (\%) & ${ }^{\circ}$ Brix & SST/ATT \\
\hline 01 - Sabor tangerina & $1,42 \pm 0,01^{1}$ & 9,4 & 6,6 \\
02 - Sabor abacaxi com hortelã & $0,76 \pm 0,04^{1}$ & 7,15 & 9,0 \\
03 - Sabor goiaba & $0,96 \pm 0,06^{1}$ & 7,1 & 7,0 \\
04 - Sabor cajá & $1,40 \pm 0,02^{1}$ & 10,4 & 5,0 \\
05 - Sabor abacaxi & $0,53 \pm 0,04^{1}$ & 2,7 & 8,0 \\
06 - Sabor acerola & $0,74 \pm 0,03^{2}$ & 6,15 & 19,0 \\
07 - Sabor graviola & $0,61 \pm 0,02^{1}$ & 11,6 & 57,0 \\
08 - Sabor manga & $0,25 \pm 0,0002^{1}$ & 14,3 & 9,0 \\
09 - Sabor uva & $1,09 \pm 0,0003^{3}$ & 10,0 & 3,0 \\
10 - Sabor tamarindo & $2,18 \pm 0,06^{3}$ & 7,25 & 3,0 \\
11 - Sabor maracujá & $1,66 \pm 0,17^{1}$ & 5,75 & 28,0 \\
12 - Sabor caju & $0,39 \pm 0,002^{2}$ & 11,00 & 23,0 \\
13 - Sabor ameixa & $0,33 \pm 0,003^{2}$ & 7,9 & 10,0 \\
14 - Sabor graviola & $0,39 \pm 0,002^{1}$ & 3,9 & 10,0 \\
15 - Sabor goiaba & $0,40 \pm 0,03^{1}$ & 4,0 &
\end{tabular}

Onde: ${ }^{1}$ ácido cítrico; ${ }^{2}$ ácido málico e ${ }^{3}$ ácido tartárico.

\section{Ácido ascórbico e Açúcares redutores}

O ácido ascórbico (vitamina C) é largamente empregado como agente antioxidante para estabilizar a cor e o aroma do alimento e conservante. Esse composto é utilizado em enriquecimento de alimentos ou restauração, a níveis normais, do valor nutricional perdido do seu teor durante o processamento (CARDELLO, 1998). A determinação do conteúdo de ácido ascórbico em frutas e de seus produtos é importante, pois além de seu papel fundamental na nutrição humana, sua degradação pode favorecer o escurecimento não enzimático e causar aparecimento de sabor estranho (CARDELLO, 1998). Na Tabela 3 é apresentada a concentração de ácido ascórbico nas amostras, e se observa que os teores variaram de 1,20 a 401,74 (mg/100g). Como esperado a amostra 06 - sabor acerola foi a que apresentou maior teor de ácido ascórbico em virtude de que a fruta que deu origem a polpa é reconhecida por ser uma excelente fonte de Vitamina C. Esse parâmetro também apresenta teor mínimo controlado pela legislação em vigor, de acordo com a fruta que deu origem a polpa, e que pode variar de 0,32 a 800 $\mathrm{mg} / 100 \mathrm{~g}$ (BRASIL, 2000). Todas as polpas encontram-se dentro dos padrões exigidos. Todas as polpas avaliadas apresentaram valores de concentração inferiores aos citados por BUENO (2002), PINHEIRO (2006) e CANUTO (2010). Os baixos teores de ácido ascórbico encontrados nas polpas analisadas pode ser explicado pelo fato de que o conteúdo de vitamina $\mathrm{C}$ também tende a diminuir durante o processo de maturação das frutas e bem como pelas condições de processamento e armazenamento (CECCHI, H, M., 2003).

Os açúcares (glicídios ou hidratados de carbono) estão presentes na forma nas frutas na forma livre ou combinada e conferem o grau de doçura destas, têm função estrutural e são fontes de energia para vários processos metabólicos, como a síntese de proteína e lipídios (KLUGE et al., 1997). Neste grupo tem-se variadas substâncias tais como os monossacarídeos, glicose e frutose, os dissacarídeos como a sacarose e os polissacarídeos como o amido e a celulose (KLUGE et al., 1997). Os monossacarídeos são açúcares redutores por possuírem grupo carbonílico e cetônico livre, são capazes de se oxidarem na presença de agentes oxidantes em soluções alcalinas (CECCHI, H, M., 2003). Os açúcares são também responsáveis pelo flavour, pela coloração e pela textura do fruto, sendo a glicose, frutose e sacarose os principais. Na Tabela 3, é apresentado os valores referentes às concentrações de açúcares redutores nas amostras analisadas, e se observa que o teores variaram de 0,46 a 1,50\%. Os resultados obtidos para esse parâmetro são distintos dos descritos por BUENO (2002) e PINHEIRO (2006). Em quatro amostras de polpas de frutas não foi possível a determinação quantitativa de açúcares redutores, que pode ser explicado pela adição de água na elaboração da polpa, o que acarretou a diminuição da concentração dos açúcares redutores nestas polpas de frutas. 
Tabela 3. Valores médios de ácido ascórbico $(\mathrm{mg} / 100 \mathrm{~g})$ e açúcares redutores (\%) nas amostras das polpas analisadas.

\begin{tabular}{|c|c|c|c|}
\hline Amostra & Cidade & Vitamina C (mg/100g) & Açúcares redutores (\%) \\
\hline $01-$ Sabor tangerina & Uiraúna & $1,59 \pm 0,20$ & $0,62 \pm 0,00$ \\
\hline 02 - Saborabacaxi com hortelã & Uiraúna & $1,20 \pm 0,20$ & $1,50 \pm 0,02$ \\
\hline 03 - Sabor goiaba & Uiraúna & $4,35 \pm 0,84$ & $0,66 \pm 0,19$ \\
\hline 04 - Sabor cajá & Pombal & $8,69 \pm 0,91$ & $1,01 \pm 0,01$ \\
\hline 05 - Sabor abacaxi & Pombal & $2,04 \pm 0,18$ & $0,48 \pm 0,01$ \\
\hline 06 - Sabor acerola & Pombal & $401,74 \pm 8,38$ & $1,01 \pm 0,01$ \\
\hline 07 - Sabor graviola & Patos & $5,54 \pm 0,24$ & $0,68 \pm 0,01$ \\
\hline 08 - Sabor manga & Patos & $2,52 \pm 0,03$ & $1,08 \pm 0,05$ \\
\hline 09 - Sabor uva & Patos & $8,91 \pm 4,08$ & $0,58 \pm 0,00$ \\
\hline 10- Sabor tamarindo & Cajazeiras & $9,13 \pm 0,04$ & $0,46 \pm 0,00$ \\
\hline 11- Sabor maracujá & Cajazeiras & $6,21 \pm 0,05$ & $0,46 \pm 0,04$ \\
\hline 12- Sabor caju & Cajazeiras & $12,23 \pm 0,06$ & n.d.* \\
\hline 13- Sabor ameixa & Sousa & $8,62 \pm 0,10$ & n.d.* \\
\hline 14- Sabor graviola & Sousa & $4,74 \pm 0,00$ & n.d.* \\
\hline 15- Sabor goiaba & Sousa & $6,59 \pm 0,03$ & n.d.* \\
\hline
\end{tabular}

*n.d.: não detectado

\section{CONCLUSÕES}

Das 15 amostras de polpas analisadas verificou-se que as amostras apresentaram teores de acidez e cinzas dentro das especificações da legislação brasileira, entretanto, para os parâmetros pH e sólidos solúveis uma (01) amostra e três (03) amostras estão fora das especificações da legislação,

respectivamente.

Quanto às concentrações de ácido ascórbico nas amostras analisadas verificou-se que todas as amostras apresentaram valores de acordo com as especificações estabelecidas pela legislação brasileira. Estes resultados refletem a real situação da qualidade físico-química das polpas de frutas comercializadas nas cidades do alto sertão paraibano e demonstram que há a necessidade dos fabricantes padronizar o processo tecnológico para a obtenção de polpas de frutas de qualidade a fim de atender as exigências estabelecidas na legislação brasileira vigente. Por sua vez, as autoridades fiscalizadoras devem tomar providências mais intensivas a fim de corrigir as irregularidades encontradas, devido aos aspectos legais, de direitos do consumidor e de saúde pública.

\section{REFERÊNCIAS}

AMARO, A. P.; BONILHA, P. R. M.; MONTEIRO, M. Efeito do tratamento térmico nas características físicoquímicas e microbiológicas da polpa de maracujá. Alimentos e Nutrição, v. 13, p. 151-162, 2002.

AMORIM, G. M.; SANTOS, T. C.; PACHECO, C. S. V.; TAVARES, I. M. C.; FRANCO, M. Avaliação microbiológica, físico-química e sensorial de polpas de frutas comercializadas em Itapetinga-BA. Enciclopédia Biosfera, v.6, p.1-8, 2002.
BRASIL. Leis, decretos, etc. Instrução Normativa $N^{\circ}$. 1, de 7 de janeiro de 2000. Regulamento técnico geral para fixação dos padrões de identidade e qualidade para polpa de fruta. Ministério de Estado da Agricultura e do Abastecimento.. Diário Oficial da União No $\mathrm{N}^{\circ}$ 6, Brasília, 10 de jan de 2000, Seção I., p. 54-58.

BUENO, S. M.; LOPES, M. R. V.; GRACIANO, R. A. S.; FERNANDES, E. C. B.; GARCIA-CRUZ, C. H. Avaliação da qualidade de Polpas de Frutas Congeladas, Revista do Instituto Adolfo Lutz, v. 62, p.121-126, 2002.

CANUto,G. A. B.; XAVIER, A. A. O; NEVES, L. C . Caracterização físico-química de Polpas de Frutos da Amazônia e sua correlação com a atividade anti-radical livre. Rev. Bras. Frutic., Jaboticabal - SP, v. 32, n. 4, p. 11961205, Dezembro 2010.

CARDELLO, H. M. A.; CARDELLO, L. Teor de vitamina C, atividade de ascorbato oxidase e perfil sensorial de manga (Mangífera índica L.) var. haden, durante o amadurecimento, Ciência e Tecnologia de Alimentos, v.18, n.2, p. 211-217, 1998.

CECCHI, H. M. Fundamentos teóricos e práticos em análise de alimentos, $2^{\circ} \mathrm{Ed}$. rev., Campinas - SP, Editora da UNICAMP, 2003, 202p.

CHITARRA, M. I. F.; CHITARRA, A. B.; ALVES, R. E. Pós-colheita de frutas e hortaliças: fisiologia e manuseio. $2^{\circ}$ Edição rev. e amp., Lavras-MG, Editora da UFLA, 2005, $785 \mathrm{p}$.

COSTA, T. A.; VIEIRA, R. F. Polpa congelada de acerola: conveniência e qualidade nutricional, v. 25, abr. 2003. 
Disponível em: 〈www.clubedofazendeiro.com.br>. Acesso em: 18 abril, 2014.

INSTITUTO ADOLFO LUTZ. Normas analíticas, métodos químicos e físicos para análises de alimentos. 4ed. São Paulo: IAL, 2008.v.1533p.

KLUGE, R. A.; NACHTIGAL, J. C.; FACHINELlO, J. C.; BILHALVA, A. B. Fisiologia e manejo pós colheita de frutas de clima temperado. Pelotas, UFPEL, 1997, 163p.

LIMA, R. M. T ; FIGUEIREDO, R. W.; MAIA, G. A; SOUSA, P. H. M.; FIGUEIREDO, E. A. T.; RODRIGUES, C. S. Avaliação da estabilidade química, físico-química e microbiológica de polpas de acerola orgânica pasteurizada e não pasteurizada. Ciência Rural, Santa Maria, Online. 42.2 (2012): 367-373.

MACHADO, S.S; TAVARES, J. T. Q.; CARDOSO, R. L.; MACHADO, C. S. ; SOUZA, K. E. P. Caracterização de polpas de frutas tropicais congeladas comercializadas no Recôncavo Baiano. Revista Ciência Agronômica, v.38, n.2, p.158-163, 2007.

MUSSER, R. S. ; LEMOS, M. A.; LIMA, V. L. A. G.; MÉLO, E. A.; LEDERMAN, I. E.; SANTOS, V. F. Características físico-químicas de acerola do banco ativo de germoplasma em Pernambuco. Ciência e Tecnologia de Alimentos, v. 4, n.4, p. 556-561, 2004.
OLIVEIRA, M. E. B.; BASTOS, M. S. R.; FEITOSA, T.; BRANCO, M. A .A .C.; SILVA, M. G. G. Avaliação de parâmetros de qualidade físico-químicos de polpas congeladas de acerola, cajá e caju. Ciências e Tecnologia de Alimentos, v. 19, n. 3, p. 326-332, 1999.

PEREIRA, J. M. A. T. K.; OLIVEIRA, K. A. M.; SOARES, N. F. F.; GONÇALVES, M. P. J. C.; PINTO, C. L. O. Avaliação da qualidade físico-química, microbiológica e microscópica de polpas de frutas congeladas comercializadas na cidade de Viçosa-MG, Alimentos \& Nutrição, v. 17, n. 4, p.437-442, 2006.

PINHEIRO, A. M. et al. Qualidade de sucos de frutas integrais, Ciências e Tecnologia de Alimentos, CampinasSP, Vol. 26, 2006.

PIO, R.; RAMOS, J. D.; MENDONÇA, V.; GONTIJO, T. C. A.; RUFINI, J. C. M.; JUNQUEIRA, K. P. Caracterização físico-química dos frutos de sete seleções de maracujazeiroamarelo para a região de Lavras-MG. Revista Ceres, v. 50, n. 291, p. 573-582, 2003.

RAIMUNDO, K.; MAGRI, R. S.; SIMIONATO, E. M. R. S.; SAMPAIO, A. C. Avaliação física e química da polpa de maracujá congelada comercializada na região de Bauru. Revista Brasileira de Fruticultura, v. 31, n. 2, p. 539-543, 2009. 